\title{
Parametric Hull Design with Rational Bézier Curves
}

\author{
Antonio Mancuso $^{1}$, Antonio Saporito ${ }^{1(\otimes)}$, and Davide Tumino ${ }^{2}$ \\ 1 Dipartimento di Ingegneria, Università degli Studi di Palermo, Viale delle Scienze, \\ 90127 Palermo, Italy \\ antonio.saporito@unipa.it \\ 2 Facoltà di Ingegneria e Architettura, Università degli Studi di Enna Kore, \\ Cittadella Universitaria, 94100 Enna, Italy
}

\begin{abstract}
In this paper, a tool able to support the sailing yacht designer during the early stage of the design process has been developed. Quadratic and cubic Rational Bézier curves have been selected to describe the main curves defining the hull of a sailing yacht. The adopted approach is based upon the definition of a set of parameters, say the length of water line, the beam of the waterline, canoe body draft and some dimensionless coefficients according to the traditional way of the yacht designer. Some geometrical constraints imposed on the curves (e.g. continuity, endpoint angles) have been conceived aimed to avoid unreasonable shapes. These curves can be imported in any commercial CAD software and used as a frame to fit with a surface. The algorithm and the related Graphical User Interface (GUI) have been written in Visual Basic for Excel. To test the usability and the precision of the tool, two sailboats with different characteristics have been replicated. The rebuilt version of the hulls is very close to the original ones both in terms of shape and dimensionless coefficients.
\end{abstract}

Keywords: Rational Bézier curves $\cdot$ Sailing yacht design $\cdot$ CAD

\section{Introduction}

In a work of any engineer, the design is often the central and more important part of the entire process. In a wide range of industries, such as automobile, aircraft and shipbuilding [1], the first step of the process consists of finding an existing well designed geometry to be used as a benchmark for the new model. As far as the maritime field, it is interesting to notice that the design approach is mostly based on the traditional design techniques of trial-and-error. Consequently, the obtained results are highly dependent on the experience of the designer [2,3]. To facilitate the design of hulls, naval engineers are investigating the possibility to define the so-called Hull Equation [4]. This equation should be able to describe, from a mathematical point of view the hull of a sailboat, a motorboat or a ship. Although an intensive effort in this sense, nowadays is not possible to describe the hull with a single one equation because the geometry of a hull depends on several parameters and most of them are related one each other [5]. Several works where authors 
present methods to generate a quick but detailed preliminary design or, on the other hand, approaches to optimize the geometry can be found in the literature. For instance, in [6] a design tool is developed using cubic polynomial expressions to define the control curves of a hull. In [7] cubic Bézier curves and the curve-plane intersection method are selected to properly design a submarine hull. Also [8] and [2] propose a new design framework to generate the parametric design and modification of yacht hulls. In particular, the hull is split into three regions to assure better design flexibility. Splitting the whole hull domain into sub-domains is a common practice as can be observed in [9] where the hull has two domains, one below the chine and one above the chine. Other authors were more focused on the optimization phase as in [10] where a novel simultaneous engineering design approach has been proposed or in [2] where an interactive design approach for hull forms optimization is developed. In this work, a numerical tool able to help the yacht designer to properly define and modify the hull form of a sailboat has been written.

The approach to the problem has been described in Sect. 2. It consists of the definition of a curves frame, modeled with Rational Bézier curves depending on yacht measurements (e.g. length, beam, draft) and some dimensionless coefficients. To avoid unreasonable shapes, constraints to the control points have been imposed. The efficiency of the tool is demonstrated in Sect. 3, where two different hull forms have been rebuilt and the obtained results compared with the original ones.

\section{Design Approach}

The shape of the hull is defined by three sections (fore, mid and aft), three longitudinal curves (sheer, chine and keel) and the right ahead. In this way, the whole domain is divided into three parts, as can be seen in Fig. 1. The curves have been modeled with rational Bézier curves of second and third-degree. The design variables of the problem are the Cartesian coordinates of the control points and the tangency of the curves at their ends. Rational Bézier curves [11] are defined by the following Eq. (1):

$$
\frac{\sum_{i=0}^{n} w_{i} B_{i, n}(t) P_{i}}{\sum_{i=0}^{n} w_{i} B_{i, n}(t)}
$$

where $B_{i, n}$ are the Bernstein polynomials while $P_{i}$ and $w_{i}$ are the control points and the weights respectively.

Rational Bézier curves differ from the Bézier curves because it is possible to increase or decrease the effect of each control point to define the shape of the curve. In this way, the designer can modify the fullness of each curve, according to the related dimensionless coefficient, without losing the condition of continuity because the tangency at the ending points of the curve is not influenced by the value of the weights.

Sections are defined with rational Bézier curves of second degree and each of them is composed of two curves: one starting from the keel to the chine and the second one starting from the chine to the sheer. In this way, it is possible to generate a wide range of shapes including sections with or without a hard chine.

To assure G0 continuity of the section (in case of hard chine hull) the position of the control points of the two curves at the chine shall be coincident. The G1 continuity (round bilge hull) is assured controlling the tangency of the curves in the common point 


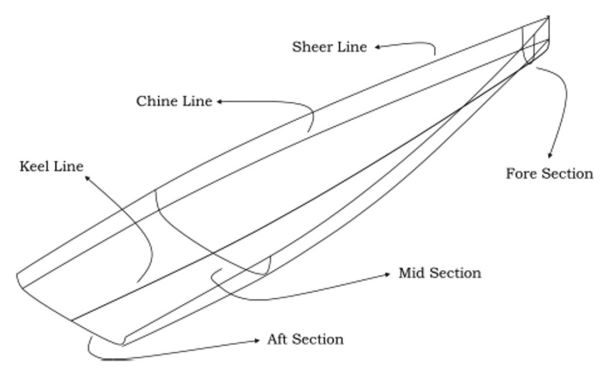

Fig. 1. Curves frame used to define the hull surface.

(always lying on the chine). The algorithm and the related Graphical User Interface (GUI) have been written in Visual Basic for Excel.

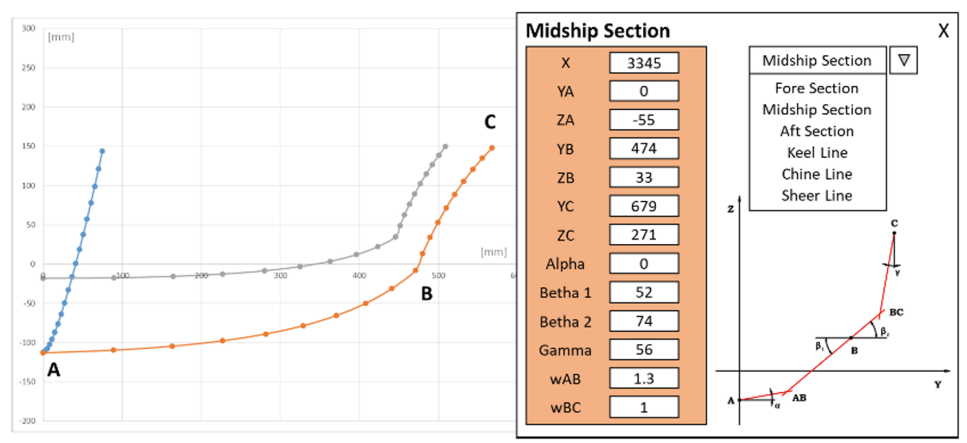

Fig. 2. Graphical User Interface of the tool developed in Visual Basic for Excel. Plane YZ.

The designer can modify the shape of each curve, by changing the values of the Cartesian coordinates $\left(\mathrm{Y}_{\mathrm{A}}, \mathrm{Z}_{\mathrm{A}}, \mathrm{Y}_{\mathrm{B}}, \mathrm{Z}_{\mathrm{B}}, \mathrm{Y}_{\mathrm{C}}, \mathrm{Z}_{\mathrm{C}}\right)$, the angles at the ends of the two curves $\left(\alpha, \beta_{1}, \beta_{2}\right.$ and $\left.\gamma\right)$ and, if necessary, the weights $w$, as shown in Fig. 2.

The keel line is also defined with rational Bézier curves of second degree with the same methodology but the value of $\beta_{1}, \beta_{2}$ are always the same to assure the G1 continuity in every part of the curve.

To properly represent chine and sheer lines rational Bézier curves of third-degree are needed. This is due to the nature of these curves that, differently from sections and keel line, are not lying on a plane. Using high order curves, in this case, helps the designer to modify the shape of the curves in both the projection planes $\mathrm{XY}$ and $\mathrm{XZ}$ as shown in Fig. 3.

A "*.pts" file, consisting of three-column list of the points' spatial coordinates (X Y Z), for each curve is automatically generated and imported in PTC Creo 4.0. An internal macro firstly generate the surface over the imported curves frame and then calculate areas and mass properties. If the design is not as good as expected the designer can modify the curves in Excel to obtain a new configuration without redesigning the entire model but just updating the "*.pts" files. 

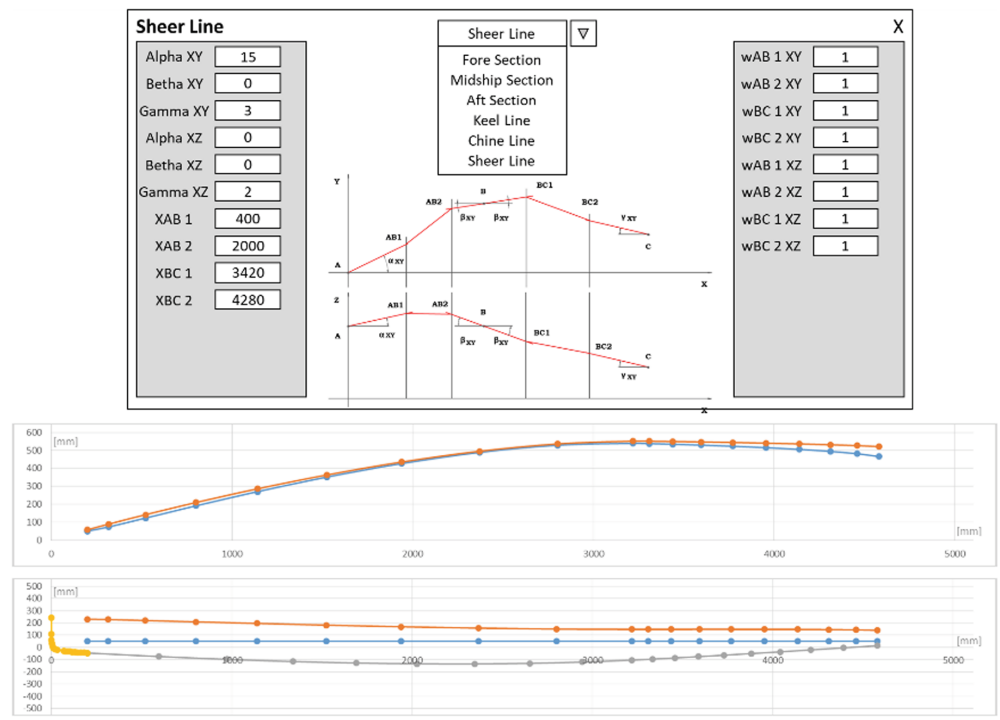

Fig. 3. Graphical User Interface of the tool developed in Visual Basic for Excel. Plane XY and XZ.

\section{Case Study}

To test the tool, the authors replicated two sailing dinghies participating to the 1001VELAcup competition (a sailing dinghy race held yearly in Italy; more details can be found at www.1001velacup.eu). The original CAD models of the two hulls (a round bilge hull and a hard chine hull) were defined by means of cubic B-spline surfaces over a set of about $20 \times 10$ control points. Starting from these models, the curves frame as defined in Fig. 1 have been obtained and placed as background images for the rebuilding process, following the procedure described in the previous section. Although the rebuilt curves have been generated starting from few information (a set of 9 points and 9 angles at all), a good match has been found.
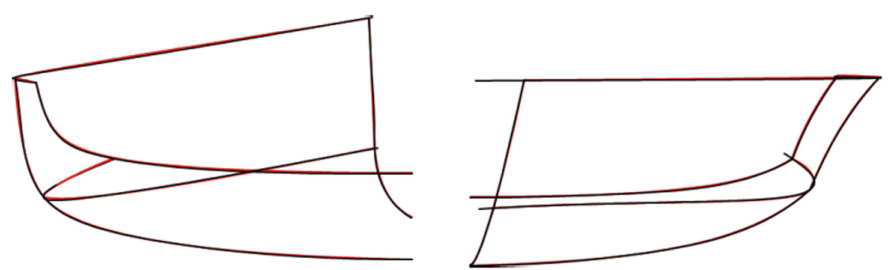

Fig. 4. Original curves (black) and rebuilt curves (red): round bilge (left) and hard chine (right)

Particularly, Fig. 4 shows the overlap of the original and rebuilt curves, while Fig. 5 shows the cut-off of the rebuilt surfaces in CREO with transversal planes to show the sections (red curves), with horizontal planes to show the waterlines (blue curves) and with 
longitudinal planes to show the buttocks (green curves). A well faired curves frame has been obtained without undesired changes in slope or curvature confirming the goodness of the proposed approach.

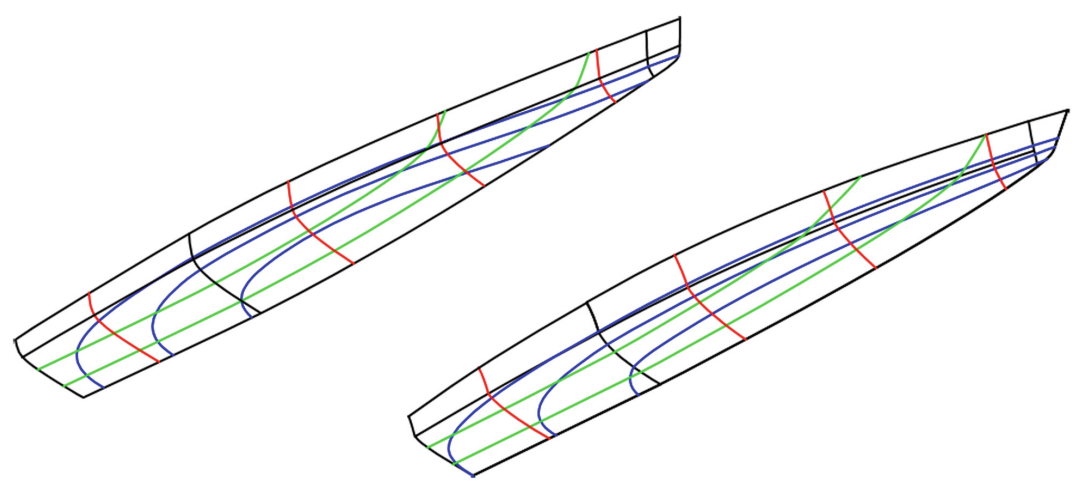

Fig. 5. Rebuilt hull surfaces: round bilge (left) and hard chine (right)

Once the geometry of the hulls is defined, the main characteristics of the two sailboats are automatically calculated. Table 1 shows the comparison of the main hull characteristics whose definitions can be found in [5].

Table 1. Main characteristic comparison between original and rebuilt hulls.

\begin{tabular}{|c|c|c|c|c|c|c|}
\hline \multirow[t]{2}{*}{ Characteristics } & \multirow[t]{2}{*}{ Symbol } & \multirow[t]{2}{*}{ Unit } & \multicolumn{2}{|c|}{ Round bilge } & \multicolumn{2}{|c|}{ Hard chine } \\
\hline & & & Original & Rebuilt & Original & Rebuilt \\
\hline Displacement & $\nabla$ & $\mathrm{m}^{3}$ & 0.238 & 0.233 & 0.262 & 0.263 \\
\hline Length overall & $\mathrm{L}_{\mathrm{OA}}$ & $\mathrm{m}$ & 4.60 & 4.60 & 4.60 & 4.60 \\
\hline Length water line & $\mathrm{L}_{\mathrm{WL}}$ & $\mathrm{m}$ & 4.40 & 4.42 & 4.49 & 4.49 \\
\hline $\begin{array}{l}\text { Max beam water } \\
\text { line }\end{array}$ & $\mathrm{B}_{\mathrm{WL}}$ & $\mathrm{m}$ & 1.05 & 1.05 & 0.95 & 0.95 \\
\hline Wetted surface & $\mathrm{S}_{\mathrm{W}}$ & $\mathrm{m}^{2}$ & 3.38 & 3.40 & 3.46 & 3.50 \\
\hline Water plane area & $A_{W}$ & $\mathrm{~m}^{2}$ & 3.14 & 3.17 & 3.10 & 3.14 \\
\hline $\begin{array}{l}\text { Max transversal } \\
\text { area }\end{array}$ & $\mathrm{A}_{\mathrm{X}}$ & $\mathrm{m}^{2}$ & 0.107 & 0.103 & 0.094 & 0.093 \\
\hline $\begin{array}{l}\text { Long. centre of } \\
\text { buoyancy }\end{array}$ & LCB & $\mathrm{m}$ & 2.48 & 2.52 & 2.25 & 2.26 \\
\hline $\begin{array}{l}\text { Long. centre of } \\
\text { flotation }\end{array}$ & LCF & $\mathrm{m}$ & 2.68 & 2.67 & 2.60 & 2.60 \\
\hline Max draught & $\mathrm{T}_{\mathrm{c}}$ & $\mathrm{m}$ & 0.14 & 0.14 & 0.17 & 0.17 \\
\hline
\end{tabular}


Concerning length, areas and volume coefficients, a maximum deviations close to $1 \%$ has been achieved between original and rebuilt hulls coefficients. This value is lower than the sensitivity of the most common numerical application like, for instance, the bare hull resistance estimation [12].

\section{Conclusion}

In this work, a tool and the relative methodology to design hulls of sailing boats is presented. The algorithm and the related Graphical User Interface (GUI) have been written in Visual Basic for Excel. A total of seven Bézier curves of the second and thirddegree are selected to define the geometry of the hull. To prove the validity of the tool and the applied approach, two existing sailboat hulls have been successfully replicated.

\section{References}

1. Nam, J., Bang, N.S.: A curve based hull form variation with geometric constraints of area and centroid. Ocean Eng. 133, 1-8 (2017)

2. Khan, S., Gunpinar, E., Sener, B.: GenYacht: an interactive generative design system for computer-aided yacht hull design. Ocean Eng. 191, 106462 (2019)

3. Cirello, A., Cucinotta, F., Ingrassia, T., Nigrelli, V., Sfravara, F.: Fluid-structure interaction of downwind sails: a new computational method. J. Mar. Sci. Technol. 24, 86-97 (2019)

4. Mancuso, A.: Parametric design of sailing hull shapes. Ocean Eng. 33(2), 234-246 (2006)

5. Larsson, L., Eliasson, R.E., Orych, M.: Principles of Yacht Design. McGraw-Hill Education, New York (2014)

6. Calkins, D.E., Schachter, R.D., Oliveira, L.T.: An automated computational method for planing hull form definition in concept design. Ocean Eng. 28(3), 297-327 (2001)

7. Chrismianto, D., Zakki, A.F., Arswendo, B., Kim, D.J.: Development of cubic Bezier curve and curve-plane intersection method for parametric submarine hull form design to optimize hull resistance using CFD. Mar. Sci. Appl. 14, 399-405 (2015)

8. Khan, S., Gunpinar, E., Dogan, K.M.: A novel design framework for generation and parametric modification of yacht hull surfaces. Ocean Eng. 136, 243-259 (2017)

9. Pérez-Arribas, F.: Parametric generation of planing hulls. Ocean Eng. 81, 89-104 (2014)

10. Ingrassia, T., Mancuso, A., Nigrelli, V., Tumino, D.: A multi-technique simultaneous approach for the design of a sailing yacht. Int. J. Interact. Des. Manuf. 11, 19-30 (2017)

11. Sederberg, T.W.: Computer Aided Geometric Design Course Notes. Computer Aided Geometric Design. BYU Scholars Archive (2012)

12. Keuning, J.A., Katgert, M.: A bare hull resistance prediction method derived from the results of the delft systematic yacht hull series extended to higher speeds. In: International Conference on Innovation in High Performance Sailing Yachts, Lorient, France (2008) 
Open Access This chapter is licensed under the terms of the Creative Commons Attribution 4.0 International License (http://creativecommons.org/licenses/by/4.0/), which permits use, sharing, adaptation, distribution and reproduction in any medium or format, as long as you give appropriate credit to the original author(s) and the source, provide a link to the Creative Commons license and indicate if changes were made.

The images or other third party material in this chapter are included in the chapter's Creative Commons license, unless indicated otherwise in a credit line to the material. If material is not included in the chapter's Creative Commons license and your intended use is not permitted by statutory regulation or exceeds the permitted use, you will need to obtain permission directly from the copyright holder.

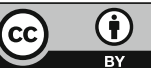

